\title{
Women with Disabilities in Nepal
}

\author{
Binod Khanda Timilsana ${ }^{1}$
}

\begin{abstract}
The women who have one or more impairments and experience barriers in society are the women with disability (WWD). Disabled women of all ages, in rural and urban areas, regardless of the severity of the impairment, sexual preference and cultural background or whether they live in the community or an institution are recognized as the WWD. As the Person with Disabilities are deprived, isolated, marginalized and excluded groups of the society, the women who have disability are one of the components of them. The social status of disabled women varies according to individual circumstances and to the country in which they live. Being a member of United Nations, Nepal recognized the human rights of people with disability in the year 1981. Accordingly, it enacted a special law known as the Disabled Persons Protection and Welfare Act, 1982 but even after 36 years of existence, the people with disabilities are often excluded from the mainstream of society and denied their human rights. Nepal is rich with legislative provisions but there is discrepancy between legislation and practices. Social security system is very poor in Nepal; disabled as well as economically marginalized people have not received any kind of social protection (food, shelter, clothes, health, education, and training). The strongest rights to social security may turn out to be nothing more than unfulfilled promises. Again most of the services are situated in urban areas and disabled people from rural areas at more risk. So it is mandatory to cater necessary services to all women with disabilities living in any part of Nepal for the respect, protect and fulfilling the commitment of government by human rights Instruments.
\end{abstract}

Key Terms: Women with Disabilities, RPWD, Human Rights of Disabilities, special protections

\section{General Background}

The term disability refers vague situation of an individual. Disability in general is the condition on which a person cannot perform daily activities properly as normal person. 'It is described as having functional/partial problems in carrying out day-to-day activities i.e. a 'disabled' is any person unable to ensure by himself or herself, wholly or partly, the necessities of a normal individual and or social life, as a result of a deficiency, either congenital or not in his physical or mental capabilities. Prevailing illiteracy, ignorance, and negative perception on the disability in the society it is considered as the punishment of the god for some sin committed in the past life but it is not so. It occurs either congenital (by birth) or acquired due to accident or as a result of diseases or due to poverty prevailed in the society. It is a human reality that occurs in all the ages from birth to old age'.

1 Mr. Timilsana is lecturer of Department of Mathematics in Saptagandaki Multiple Campus, Email: binodtimilsana@gmail.com 


\section{Definition of Disability}

In present context there has been a debate on disability with much argument about how it is defined and conceptualized. Nepalese government has defined it as the NPPAD-2006 states "situation of feeling difficulties to perform daily activities due to physical impairedness, infrastructural, social, and cultural and communication barriers owing to the problems in body organs and systems." Similarly, The International Classification of Functioning (ICF) defines it as the outcomes of the interaction between a person with impairment and environmental and attitudinal barriers s/he may face. Similarly a study conducted by National Planning Commission and UNICEF in 2001 has been defined 'disability as the person who cannot perform the daily activities of the life considered normal for a human being within the specified age and where the person needed special care, support and some sort of rehabilitation services.

\section{Women with Disability}

The women who have one or more impairments and experience barriers in society are the women with disability (WWD). Both disabled girls and women of all ages, in rural and urban areas, regardless of the severity of the impairment, sexual preference and cultural background or whether they live in the community or an institution are recognized as the Women With Disabilities (WWD). As the Person With Disabilities (PWD) are deprived, isolated, marginalized and excluded groups of the society, the women who have disability are one of the components of them. The social status of disabled women varies according to individual circumstances and to the country in which they live. 'Disabled women in developing countries usually experience a particular disadvantage. They are one of the most unrecognized groups among the disability of the society. They are found existing in the lowest status as a result they are multiply disadvantages through their status as a woman, as women with disabilities and, are over represented among people living in absolute poverty. They are cast down, stigmatized, rejected, and excluded from family, community and even from the government authority. As the Asian Institute of Technology 'the women with disability are more excluded group of the society.' Among the people with disability the WWD lead isolated lives as they are not allowed to move out of their own houses.

Thus, disabled women are women who have one or more impairments and experience barriers in society. We include disabled girls and women of all ages, in rural and urban areas, regardless of the severity of the impairment regardless of sexual preference and regardless of cultural background or whether they live in the community or an institution.

Being a member of United Nations, Nepal recognized the human rights of people with disability in the year 1981 when Nepal along with world community, Celebrated the International Year of Disabled Persons. Accordingly, it enacted a special law known as the Disabled Persons Protection and Welfare Act, 1982 but even after 26 years of existence, the people with disabilities are often excluded from the mainstream of society and denied their human rights. The DPWA and other laws give certain rights and privileges to the disabled people but most of these rights remain in the law books and have not been used in reality. People with disability have not received free education, health facilities, employment etc. as mentioned in law. 


\section{Rationale and Objectives of the Study}

People with disabilities are disadvantaged and discriminated in every sphere of their life. It is even worse when it comes to disabled women because society treats men and women differently and mostly priority goes to men whether he is disabled or not. In our country, disabled women are not considered for employment and that decrease self-confidence. Men who are disabled only lose half of their self-confidence whereas women who are disabled lose much more due to discrimination between them. The condition of women is strictly controlled by patriarchal norms of the society. Women in our society are respected as half citizens and their position in lower than men. This situation directly affects their self-confidence, self-esteem, and eventually their health status in general and disability in particular.

Women with disabilities are objectified and cost down. They face discrimination at home, in distribution of income and benefits. They are also excluded from participation in the social activities. They experience more difficulties finding job and in case they happen to work, their income is much lower than able women as well as lower than men with or without disabilities. Lack of knowledge on disability and negative attitude of public, women with disabilities face rejection while looking for job. In addition poverty increases the incidence of disabilities among young girls and women. Disabled women experience poverty more than anybody else because they don't have access to any resources. For the disabled women, life can be very tough specially when coping with everyday activities without much support from family and government. Young disabled women suffer more than young disabled men because disabled women find it more difficult to get married. People assume that having disabled women in the family will bring bad luck. Women do not have the right to inherit their parent's property and are considered to become a burden for the family. Women's chances of visiting hospitals are very rare; they suffer without any medical care whatever. This is due to gender discrimination as well as lack of knowledge about causes and prevention on disabilities. Within same family disabled boy gets treatment and necessary appliances and education whereas disabled girl is being kept in the corner of the house. These are the central problem faced by women with disabilities.

Though the government, through its legislation, has taken some steps to support the large community of people with disabilities in Nepal, most programs remain ineffective due to the lack of commitment and inadequate resources. The government of Nepal has provided a framework for the implementation of legal, progressive and economic activities but these activities are only on paper; as a result, people with disabilities continue to suffer. Certain per cent of quotas in different programs are placed for disabled people however they have not used this facility in practice. Disabled women, who are rejected from family or unable to do anything at their home due to their disabilities, don't have any place to go.

Social security system is very poor in Nepal; disabled as well as economically marginalized people have not received any kind of social protection (food, shelter, clothes, health, education, and training). The strongest rights to social security may turn out to be nothing more than unfulfilled promises. I/NGOs are 
Women with Disabilities in Nepal

trying to help people with disabilities but they can hardly cover certain per cent of disables and none of them are long term or beneficial to disabled people as long run. Again most of the services are situated in urban areas and disabled people from rural areas get nothing. So it would be better if government cater necessary services to all disables people living in any part of Nepal. Thus it is essential to study about the status of women with disabilities and to identify the causes and to identify the possible ways to minimize the partiality for women with disabilities in Nepal by the concerns. Women are generally discriminated on their rights because the society treats men and women differently and due to gender bias the WWD face compound discrimination by being both women and with disability. So, the outcomes of this study are expected to be useful to formulate policies which give guarantee for the protection of the WWD rights among the PWD and it will help to increase the social awareness for the welfare of the WWD. The objectives of this study were:

1. To identify the policies and practices to address the problems regarding the low status of women with disabilities in Nepal.

2. 2. To explore the context specific possible suggestions to formulate policies which give guarantee for the protection of the WWD's rights among the PWDs.

\section{Delimitation of the Study}

The study was literature review and individual judgments of the researcher only.

\section{Methodology}

To accomplish the objectives of the study, data and information were qualitative in nature gathered from secondary sources such as internet surfing and various published books and study reports. So, the methodology used is interpretation over information from literature.

\section{Instruments and Mechanisms for Women Rights}

\begin{tabular}{|c|c|c|}
\hline SN & Date & Name of Instruments for Women Rights \\
\hline 1 & 1949 & $\begin{array}{l}\text { Convention for the Suppression of the Traffic in Persons and of the Exploitation } \\
\text { of the Prostitution of Others }\end{array}$ \\
\hline 2 & 1951 & ILO Convention 100 on Equal Remuneration \\
\hline 3 & 1952 & Convention on Political Rights of Women \\
\hline 4 & 1956 & Supplementary Convention on the Abolition of Slavery \\
\hline 5 & 1957 & Convention on the Nationality of Married Women \\
\hline 6 & 1962 & $\begin{array}{l}\text { Convention on Consent to Marriage, Minimum Age of Marriage and } \\
\text { Registration of Marriage }\end{array}$ \\
\hline 7 & 1974 & $\begin{array}{l}\text { Declaration on the Protection of Women and Children in Emergency and } \\
\text { Armed Conflict }\end{array}$ \\
\hline 8 & 1979 & $\begin{array}{l}\text { Adoption of Convention on Elimination of All Forms of Discrimination } \\
\text { Against Women }\end{array}$ \\
\hline 9 & 1981 & CEDAW comes into force \\
\hline 10 & 2000 & Optional Protocol to CEDAW \\
\hline 11 & 2015 & The Constitution of Nepal \\
\hline
\end{tabular}


Among these instruments the Convention on the Elimination of all Forms of Discrimination Against Women, CEDAW is a milestone human rights standards to the situation of women. The significant difference that CEDAW has introduced is that it has not been limited to securing women's human rights but is also expanding the understanding of human rights itself. In doing so, it underscores the need to consciously and consistently expand and extend rights to special contexts and identities. To that extent, the long-term task of integrating gender-specific forms of violations into the general human rights framework still remains.

As the concern of mechanism, the Commission on the Status of Women (CSW) is a functional commission of the United Nations Economic and Social Council(ECOSOC). It is the principal global policy-making body dedicated exclusively to gender equality and advancement of women. Every year, representatives of Member States gather at United Nations Headquarters in New York to evaluate progress on gender equality, identify challenges, set global standards and formulate concrete policies to promote gender equality and women's empowerment worldwide. And state parties of instruments are the main implementation agencies as the indistinct part of mechanism towards the rights of women. Mainly the state are responsible to respect, protect and fulfill the rights as approved and declared by instruments.

In this regard, full realization of human rights requires states to take on three levels of responsibilities: those of respecting, fulfilling and protecting rights and freedoms. Each level is indivisibly linked to the next. Respect requires affirmation through enactment of normative standards recognizing women's human rights. This is the starting point for facilitating enjoyment of rights and freedoms, by creating environments, including institutional frameworks that enable fulfilment of the normative standards. Finally, enforceable mechanisms that can effectively protect those standards from threats of violation or redress violations. These three roles correspond to the full "recognition, enjoyment and exercise" of rights and freedoms by women as envisaged in Article 1 of the Convention on the Elimination of all Forms of Discrimination Against Women. Thus, the performance of state responsibility therefore goes beyond mere Constitutional affirmation, to undertaking a range of programmes, policies and initiatives that address public and private action in every field. Most importantly, it includes the establishment of institutional frameworks and mechanisms that effectively protect rights and freedoms from even partial infringement.

\section{Instruments for Women with Disabilities}

There are various initiatives to promote rights of persons with disabilities and to promote equal rights of men and women. In the Universal Declaration of Human Rights (1948) reference to disability in article 25, which recognizes that everyone has "the right to security in the event of unemployment, sickness, disability, widowhood, old age or other lack of livelihood in circumstances beyond his/her control". Likewise the United Nations launched a "Decade of Disabled Persons" in 1982 declared mental, physical or sensory impairment people are entitled to the same rights as all other human beings and to equal opportunities. 
As a result of the world program of Action, the United Nations declared the Decade of Disabled Person, 1983-1992. They called for effective implementation and follow up of the objectives of the International Year of Disabled Persons and for creation of equal opportunities for full participation of people with disabilities in their families, communities and countries. With regards to education, the UNESCO convention against Discrimination in education 1960 states that special education should provide similar standards as regular provisions. The Sundberg Declaration1981 proclaims that every disabled person must be able to exercise his/her fundamental rights to full access to education, training, culture and information. Similarly, the ILO Convention Concerning Vocational Rehabilitation and Employment (disabled persons) 1983, and ILO Recommendation Number 168 concerning Vocational Rehabilitation and Employment disabled persons 1983 were the first instruments to expressly stress the right to equal opportunity to work for all disabled people.

The United National Standard Rules on the Equalization of opportunities for persons with Disabilities (1993) provided a basis for international co-operation and an instrument for policy- making and actions for person with disabilities. These rules are based on the experience of the Decade (1982-1993).

Similarly, Convention on the Rights of Persons with Disabilities 2006 (CRPD) which includes 50 articles and Nepal is the party from the date of adaptation 7 May, 2010. Similarly optional protocol of CRPD which includes 18 articles and the protocol also adopted by Nepal on the same day 7 May, 2010. The major four principles 'respect for inherent dignity and individual autonomy, non-discrimination, participation in society and disabilities as a part of human diversity and humanity' are the main guidelines for the rights of persons with disabilities as well as rights of women with disabilities. Article 6 of CRPD is concern with rights of women with disabilities.

\section{Instruments in Nepal for women with disabilities}

Nepal has started to define specific policy for disabled people. International institutions have contributed toward enhancing the country's concern in this field. International human rights treaties, which are binding on states parties, have their own influence. Similarly, instruments that are not binding, such as declarations, resolutions, principles and guidelines have guided the domestic legislation. The legal provisions for the welfare and protection of disabled persons in Nepal are therefore based on several international instruments. Laws relating to the welfare of the disabled people in Nepal found in many legal instruments.

Article 11(3) says that special laws shall be made for the protection and advancement of the interests of women, children, the aged and those who are physically and mentally disabled. Article 26(9) imposes duty on the state to pursue such policies in matters of education, health and social security of orphans and disabled persons for their protection and welfare.

The Disabled Persons Protection and Welfare Act, 1982 and Rules, 1994 was the first legislation which enacted by the legislature in 1982 after the declaration of the United Nations to celebrate the year 1981 as 
Women with Disabilities in Nepal

'The International year of Disabled Persons'. The Disabled Persons Protection and welfare Act (DPWA), 1982 for the first time in Nepal has expressly granted some rights and facilities to disabled people. DPWA defines the disabled persons as those Nepali Citizens who due to physical and mental cause are incapable or unable to carry out their daily activities. It includes all those persons with speaking, hearing, seeing, manipulation and mobility disability and all mentally retarded persons. Rights and facilities granted under DPWA are given below:

\section{Educational Rights}

No fee will be charged to the disabled persons by any educational institutions. The world educational institutions as used in the Act actually denote all the schools funded by the government. Every government and Semi-government institutions have technical and vocational training programs must reserve five per cent of the total seats to the disabled persons without charging any fee provided that the training will be useful for the disabled persons. Any non-governmental or private institution that provides education and training facilities for disabled persons has the right to ask for assistance from the government as directed under DPWR.

\section{Health Facilities}

The law provides some special health facilities for the disabled people as prescribed under DPWA and DPWR. Free medical examination shall be rendered in all the hospitals of the kingdom. The DPWR clearly directs the reservations of at least two free beds for the treatment of disabled persons in any government hospital of the kingdom having more than fifty beds. Similarly, the government may provide essential assistance to those non-governmental hospitals, which offer free medical checkups, free beads or free treatment for the disabled persons. The DPWA imposes responsibility on the government to investigate the general and specific causes of disability and make essential arrangements for the treatment.

\section{Employment Facilities}

Every government and Semi-government organizations must give priority to the disabled persons in employment according to their education, training, and physical position. No discrimination shall be made among disabled employees and other employees in remuneration, facilities and service conditions. At least five per cent reservation in appropriate work for the disabled persons according to their physical capacity, training, qualification and experience may be allocated in an industrial enterprise having more than 25 employees. For the purpose of securing employment rights, suitable arrangements are to be made by the government to provide appropriate training to the disabled person.

\section{Self-Employment Facilities}

The DPWA directs the government to initiate appropriate programs for the disabled people in order to make them economically self-dependent. The government through its concerned agencies has lunched some self-employment opportunity schemes for the disabled. The social welfare council (SWC) has started to provide loans of Rs. 5000-20000 wit out collateral to any disabled persons who have no means 
or sources to conduct a business despite of his/her skill and efficiency. This scheme was initiated by the SWC in 2000, is a regular program aimed at improving the economic condition of disabled people.

\section{Traveling Facilities}

The DPWA calls for the provision of half-concession to the disabled person and one of his/her caretakers for bus, train and airplane travel. This provision is not mandatory and hence, it depends upon whether or not the concerned transport agents and companies want to provide such facilities to the disabled persons. Even the government owned transport agencies like Nepal Airlines, Sajha Yatayat and Trolley Bus services have not given such concessions to the disabled persons. There is still no seat reservation for disabled people.

\section{Free Legal aid Services}

The statement of basic human rights in the constitution and laws does not go for enough in ensuring equal rights for all citizens. People belonging to underprivileged, social and economically disadvantaged communities and disabled people need special facilities and protections from the state to enable them to enjoy the rights guaranteed by the constitution and laws. Therefore, the constitution, through its Directives principles, clearly commands that in order to secure justice for all, the state shall pursue a policy of providing free legal aid to indigent persons.

Similarly, Social Welfare Act 1992 is another instrument, which empowers the government to undertake special programs of social welfare activities aimed at different of classes of people. It aims to serve the interests and ensure the welfare of children, the old and disabled people. It works to increase people's participation in development activities, and to protect and promote the rights and interest of women.

Likewise, Local Self-government Act 1999 is also related to the rights of women with disabilities, which provides authorities to the village Development committee (VDC) and VDC Ward Committee to help in activities relating to the protection and livelihood of disadvantaged communities, as well as orphans and the helpless and disabled people of the village. It also imposes duty on the VDC to maintain records on the helpless and disabled people within the VDC and to make arrangements for their appropriate accommodation.

\section{Responsible Authorities}

At the central level, it is the Ministry of Women, Children and Social Welfare (MWCSW), which is primarily responsible for implementing the laws pertaining to the welfare of disabled people, and provides several to their needs. It derives its authority directly from DPWA to executive laws and formulates policies and programs as directed by legal instruments. The Ministry of Education and Sports, Ministry of Health, Ministry of Finance, Ministry of Local Development, Ministry of labour and Transport and Ministry of Home are also responsible to some extent for implementing the laws related to the tights and services of disabled people. DPWA clearly directs the government, particularly the Ministry of Women, Children and Social welfare to register the types of disability and the names of disabled people living in different parts of the country. 


\section{References}

Prasad, L. N. (2003). Status of People with Disability in Nepal, Kathmandu: Modern Printing Press.

Ministry of Women, Children and Social Welfare (2063 B.S.). National Policy and Plan of Action on Disability.Kathmandu: NPPAD.

NPC (2001). A Situational Analysis of Disability in Nepal. Kathmandu: National Planning Commission/ UNICEF.

Sangraula, G.P. (2014). UN Charter, UDHR and Core Human Rights Treaties and Annexes. Bhaktapur : Kathmandu School of Law.

Dhungana, B. M. (2003). The Lives of Disabled Women in Nepal: Vulnerability Without Supprot. Thailand: Asian Institute of Technology.

Sharma, J.K. (2007). A study of status of women with disabilities in Nepal. A study report to SNV-Nepal. MOES (2002). Education For All. Kathmandu : National Plan of Action.

UNICEF, (2003). Examples of Inclusive Education Nepal. A study report by Regional office for South Asia.

ILO (1989). Dispelling the shadow of Neglect. A survey on women and disabilities in six Asian and Pacific countries, Geneva.

Disabled persons, protection and Welfare Rules, 1994.

UNIFEM (2004). CEDAW: Restoring Rights to Women. A text prepared with the help of DLA. 